\title{
Oferta de Carreras de Posgrado
}

\section{Doctorados}

Doctorado en Ciencias Biológicas

Acreditada por CONEAU Cat. A, Res.

№ 735/13; reconocida por Ministerio

de Educación Res. № 580/09

Doctorado en Física

Acreditada por CONEAU Cat. A, Res.

No 783/13; reconocida por Ministerio

de Educación Res. № 784/08

Doctorado en Educación en Ciencias

Experimentales

Reconocimiento en trámite por CONEAU

y Ministerio de Educación

\section{Especializaciones}

Especialización en Bacteriología Clínica Acreditada por CONEAU Cat. A, Res. No 307/08; reconocida por Ministerio de Educación Res. № 182/10
Especialización en Administración

de la salud con orientación en Auditoría Bioquímica Integral Acreditada por CONEAU Cat. B, Res. № 408/09; reconocida por Ministerio de Educación Res. № 580/10

Especialización en Vinculación y Gestión Tecnológica

Acreditada en forma provisoria por CONEAU Res. No 920/09

\section{Maestrías}

Maestría en Salud Ambiental

Acreditada por CONEAU Cat. Bn, Res. № 209/09; reconocida por Ministerio de Educación Res. № 676/09

Maestría en Didáctica de la Ciencias Experimentales Acreditada por CONEAU Cat. A, Res. NN 182/07; reconocida por Ministerio de Educación Res. № 255/09

Maestría en Física

Cuenta con reconocimiento del Ministerio de Educación (Res. en trámite) 


\section{Reglamento de publicación}

\section{Objetivos}

La Revista de la Facultad de Bioquímica y Ciencias Biológicas (FABICIB) tiene como objetivos: a- Divulgar trabajos científicos originales, así como de revisión por invitación a expertos en los temas y de divulgación, de autores pertenecientes a la Universidad Nacional del Litoral, otras Universidades e Instituciones Científicas Nacionales y/o Extranjeras vinculadas con diferentes áreas temáticas de la ciencia : básica, bioquímica aplicada, pedagógica (esta última relacionada con trabajos de experimentación o campo), etc.

\section{Presentación}

Todo manuscrito se presentará en hojas numeradas correlativamente, a doble espacio, en papel tamaño IRAM $(21 \times 29,7 \mathrm{~cm}$.), con márgenes de $2,5 \mathrm{~cm}$ en original y dos copias impresas de alta calidad o calidad láser y cd. En el cd las figuras deberán estar en archivos separados en formato JPG y de alta resolución. Se cuidará que tengan la misma cantidad de renglones, de la misma extensión, para facilitar los cálculos de imprenta.
En la primera hoja figurarán:

a. Título del trabajo y subtítulo, si lo hubiera.

b. Apellido e iniciales de nombre del autor o autores.

c. Institución a la que pertenecen, ciudad, provincia, país, dirección postal completa, teléfono, FAX, e-mail.

No se establecerán límites arbitrarios. Los manuscritos deberán ser originales, inéditos, breves y precisos en la medida de lo posible, y adaptados a la índole de la publicación.

Los trabajos se recibirán entre el $1^{\circ}$ de enero y 31 de mayo de cada año.

\section{Ordenamiento de los textos}

Se considerará conveniente ordenar las colaboraciones de la siguiente manera:

Trabajos Científicos y Técnicos:

a. Título: deberá ser lo suficientemente claro y preciso y en lo posible ubicará al lector en el contenido del artículo. Se deberán evitar abreviaturas.

b. Autores: Apellido/s e iniciales del nombre.

c. Nombre y dirección del Establecimiento donde el trabajo fue realizado. 
d. Nombre, dirección postal completa, número de teléfono y FAX del autor a quien pueda enviarse pruebas y correspondencia.

e. Resumen analítico: deberá ser lo suficientemente preciso como para dar amplia idea del contenido del artículo. Además respetará las siguientes disposiciones:

- No deberá exceder las 150 palabras.

-Deberá poner de relieve los aspectos fundamentales del artículo, por ejemplo: los elementos nuevos que aporta y sus conclusiones.

- Deberá estar redactado de modo que el lector quede capacitado para decidir si el contenido del artículo tiene interés suficiente como para ser leído en forma completa.

- Agregar no más de 4 palabras claves.

En hoja aparte se acompañará su traducción al idioma inglés, encabezado por la palabra SUMMARY incluyendo título, y los autores. Al finalizar el mismo se citarán la palabras claves (no más de cuatro).

f. Introducción: se deberá incluir en este apartado el propósito del trabajo y su relación con estudios similares sobre el tema.

g. Materiales y Métodos: se presentará un informe breve y concreto.

h. Resultados y Discusión: deberá contener los resultados obtenidos, en los cuales se discutirán sus posibles correlaciones con otros trabajos realizados con anterioridad.

i. Conclusiones: versará fundamentalmente sobre el aporte que el trabajo presentado hace a los ya existentes y las posibilidades que el mismo brinda.

j. Referencias Bibliográficas:

- Referencias en el texto

Las referencias consignadas en el texto de los trabajos se efectuarán mencionando entre paréntesis el número correlativo correspondiente al orden de aparición.

- Referencias al final del trabajo

Las referencias completas se harán al final del trabajo con todos los detalles y responderán a las siguientes normas:

Cuando se trate de libros, se mencionará: nombre del autor o autores, año de edición, título completo del libro entre comillas, casa editora, ciudad de edición entre paréntesis, volumen en números romanos en negrita, número de página inicial y final. Por ejemplo: Bronk, J.R., 1980. "Biología Química" Compañía Editorial Continental S.A. (México), I. 178 - 199.

Cuando se trate de capítulos de libro se indicará: nombre del autor del capítulo, año, título del capítulo. En: nombre de editores, nombre del libro entre comillas, Editorial, país de edición, páginas del capítulo. Por ejemplo: Bronch, J. R., 1980. Química de la membrana celular. En: Bronch, J. R. (Ed.), "Biología Química". Compañía Editorial Continental S.A. (México), I 178-199.

Cuando se cite un artículo publicado por una revista, se seguirá el siguiente orden: nombre del autor o autores, año de edición, título completo del artículo en idioma original, nombre de la revista abreviado, volumen en negrita, número de la revista, página inicial y final. Por ejemplo: Perez, J.; Rodriguez, L.; Sanchez, P., 1971. Hipertensión in diabetes and obesity. Am. J. Physiol.

4, 29: 12 - 19 .

Cuando se trate de página de internet citar: dominio y fecha de acceso.

k. Agradecimientos: Se escribirán en hoja aparte.

I. Nota: Si el trabajo ha sido parcial o totalmente presentado a un congreso se adjuntarán los datos del mismo. 
Actualizaciones bibliográficas

y conferencias:

Versarán sobre temas de gran interés, con una amplia revisión bibliográfica y sus autores deberán ser especialistas en la materia.

Temas de divulgación y demás trabajos:

De acuerdo con el plan del autor.

\section{Nomenclatura}

Deberá utilizarse la nomenclatura de acuerdo a las normas recomendadas por los Comités Internacionales.

\section{Tablas e ilustraciones}

Todas las tablas e ilustraciones deberán ser citadas en su orden de aparición en el texto usando números arábigos.

Las tablas llevarán un encabezamiento del tipo: Tabla 1. Debajo del cual se colocará el título correspondiente. Las leyendas de las mismas se confeccionaran en la misma hoja.

Las ilustraciones Ilevarán referencias que expliquen claramente su contenido sin necesidad de recurrir al texto, deberán ser realizadas en papel de alta calidad, ser claras, nítidas y de elevado contraste para poder reducir su tamaño sin inconveniente. Llevarán numeraciones corridas y estarán confeccionadas en una sola escala para facilitar su reproducción. En hoja separada se consignarán los títulos y referencias, como así también las indicaciones respecto de su ubicación en el texto (lugar aproximado). Convendrá marcar con una flecha la posición arriba de la ilustración.

Deberán enviar las figuras en un archivo separado en formato JPG de buena calidad de imagen (600 dpi)

Las fotografías deberán ser en blanco y negro, claras y contrastadas, para facilitar su reproducción. No se aceptarán diapositivas, las que deberán reproducirse sobre papel fotográfico. Las leyendas de las fotografías deberán escribirse en página aparte.

Todos los artículos presentados serán evaluados por al menos 2 especialistas en el tema, integrantes y/o invitados especiales del Comité de Evaluación Externo. 


\section{Lista de autores}

Albornoz, M.A.

Alfaro, N.S.

Arce, A.L.

Bacchetta, C.

Briggiler Marcó, M.

Bernal, C.A.

Beltzer, A.H.

Bonelli, E.

Budini, N.

Cabagna Zenklusen, M.C.

Campana, M.

Cantora, AM.

Cerolini, R.R.A.

Chemes, S.B.

Comelli, R.N.

Corti, M.R.

Exner, E.L.

Fariña, A.C.

Follonier, $\mathbf{M}$.

Fortino, M.A.

González, M.A.

Groppelli, E.

Giacomelli, J.I.

Giuggia de Stratta, M.G.
Gutierrez, M.F.

Lassaga, S.L.

Latorre, M.E.

Latorre Rapela, M.G.

Lavandera, J.

Lerman de Abramovich, B.

Lottersberger, J.

Lurá, M.C.

Machtey, M.

Maldonado, L.M.

Marcipar, I.

Marsili, N.R.

Martinelli, M.

Maumary, $\mathbf{R}$.

Méndez, E.A.

Misetich, O.R.

Modini, LB.

Mufarrege, M.M.

Navarro, L.

Olguín, P.F.

Pavé, P.J.

Perotti, J.P.

Piattoni, C.V.

Pizarro, AV.;
Quaglino, M.B.

Reus, V.

Reutemann, A.G.

Rinaldi, P.A.

Rodríguez, M.C.

Saín, J.

Sánchez, M.L

Scalerandi, M.V.

Schenone, A.V.

Simil, E.

Simonetta, A.

Sobrero, M.S.

Sosa, C.

Talio, M.C.

Tonarelli, G.

Turino, L.N.

Vanasco, N.B.

Van de Velde, F.

Velázquez, M.M.L

Vitelleschi, M.S.

Walz, M.F.

Zerbatto, MG. 
FABICIB se diagramó y compuso en edicionesunL

y se terminó de imprimir en Docuprint, Tacuarí 123,

CABA, Buenos Aires, Argentina. Diciembre de 2013. 